\title{
Small intestinal motor abnormalities in patients with functional dyspepsia demonstrated by ambulatory manometry
}

\author{
H J A Jebbink, G P vanBerge-Henegouwen, L M A Akkermans, A J P M Smout
}

\begin{abstract}
Aims/Methods-In 30 patients with functional dyspepsia and in 20 healthy volunteers, ambulatory duodenojejunal manometry was performed to examine the interdigestive and postprandial small intestinal motility patterns in relation to symptoms.

Results-In the fasting state, the number of migrating motor complex cycles mean (SEM) was significantly lower in patients, especially in patients with dysmotility-like dyspepsia, than in control subjects $(3.8$ $(0.4), 2.6(0.5)$, and $5.3(0.7)$ cycles, respectively; $p<0.05$ ), due to a longer duration of phase II. Non-propagated and retrogradely propagated phase III activity was more prevalent in patients than in control subjects $(48 \%$ v $15 \% ; p=0.020)$. During phase II and after dinner no differences were found in contraction incidence, mean amplitude or motility index. However, $1 \frac{1}{2}$ hours after completing breakfast the motility index was higher in patients at all three recording levels $(p<0.05)$. Burst activity was more prevalent in patients than in control subjects $(22 \% v 6 \%$ of the subjects; $p=0.003)$. In $41 \%$ of the patients the symptom index was $>75 \%$.

Conclusions-These results suggest that small intestinal motor abnormalities, especially during fasting, participate in the pathogenesis of symptoms in patients with functional dyspepsia. Ambulatory manometry of the small intestine is a valuable tool to demonstrate these abnormalities in outpatients pursuing their daily activities.

(Gut 1996; 38: 694-700)
\end{abstract}

Departments of Gastroenterology H J A Jebbink $G$ vanBergeHenegouwen

A J P M Smout

and Surgery

L M A Akkermans

University Hospital Utrecht, Utrecht, the Netherlands

Correspondence to: Dr J H A Jebbink, Department of Gastroenterology, University Hospital Utrecht, PO Box $85500,3508 \mathrm{GA}$ Utrecht, the Netherlands.

Accepted for publication 7 December 1995
Keywords: functional dyspepsia, ambulatory manometry, small intestinal dysmotility.

Patients with upper abdominal symptoms occurring in the absence of an organic cause, designated as suffering from non-ulcer or functional dyspepsia, have been divided into subgroups based on their symptoms: reflux-like, ulcer-like dysmotility-like, and non-specific dyspepsia. ${ }^{2}$ However, evidence of a relation between these subgroups and underlying functional abnormalities has not been shown. ${ }^{34}$ Previous studies into the pathophysiology of non-ulcer dyspepsia have suggested several functional abnormalities, including gastric acid hypersecretion, gastrointestinal motor disorders
(Helicobacter pylori associated) gastritis, and duodenitis, psychological and neurohormonal factors. ${ }^{4-14}$

Gastric emptying and small bowel transit studies, using radionuclide techniques, showed a delayed gastric emptying and small bowel transit, especially of solid food, in about $50 \%$ of the patients with functional dyspepsia. ${ }^{4} 15-18$ Stationary short-term antroduodenal manometry, using a low compliance perfusion technique, has demonstrated postprandial antral hypomotility as the major abnormality in these patients. ${ }^{101119}$ However, studies showing a correlation between delayed gastric emptying, antral hypomotility, and symptoms in patients with functional dyspepsia are lacking. Abnormal small bowel motility in patients with functional dyspepsia has been reported less frequently. Some patients have been reported to lack the interdigestive migrating motor complex (MMC). Other patients showed clusters of high amplitude contractions at a high frequency, so called bursts. ${ }^{101920}$ It is unlikely, however, that short duration recordings obtained by stationary antroduodenal manometry will provide definitive conclusions about the MMC, because usually only a few complete MMC periods are recorded.

Recently, ambulatory manometry has been developed for longterm studies under physiological circumstances. Studies in healthy volunteers have shown that ambulatory longterm manometry of the small intestine is feasible. ${ }^{2122}$ In patients with functional dyspepsia, such a study has never been undertaken. Ambulatory manometry also offers the possibility to assess the temporal association between the patient's symptoms and motor abnormalities. The aim of this study was to examine the relation between the interdigestive and postprandial small intestinal motility patterns and dyspeptic symptoms in patients with ( $H$ pylori negative) functional dyspepsia, using the technique of ambulatory manometry.

\section{Methods}

Subjects

Thirty patients, 17 females and 13 males, aged $39.3(13 \cdot 1)$ years (mean (SD)), were included in the study. These patients were referred to the outpatient gastroenterology clinic of the University Hospital of Utrecht because of chronic unknown upper abdominal symptoms. The diagnostic investigation of the patients consisted of a physical examination, proximal endoscopy (with prepyloric biopsy for urease 
test on $H$ pylori), routine laboratory investigations, and an upper abdominal ultrasound study. The entry requirements for the study were the presence of chronic (>6 months) dyspeptic symptoms (nausea, vomiting, heartburn, retrosternal pain, epigastric pain, belching, fullness, or postprandial early satiety), with a mean symptom score for severity $>1.5$ (see later) and without a known cause. Exclusion criteria were: (a) organic gastrointestinal disease, (b) constipation (defined as straining at stools $>25 \%$ of the time or a stool frequency $<3 /$ week, or both) or diarrhoea (defined as loose or watery stools $>25 \%$ of the time or stool frequency $>3 /$ day, or both), (c) a history of peptic ulcer disease or major abdominal surgery, (d) systemic, metabolic, endocrine, neurological or psychiatric diseases, (e) use of drugs known to influence gastrointestinal motility.

Twenty healthy $H$ pylori negative volunteers served as control subjects ( 12 women and 8 men, aged $37.8(12 \cdot 0)$ years). Gastroscopy was performed to exclude organic gastrointestinal disease and to determine their $H$ pylori status. Informed consent was obtained in each case and the study protocol was approved by the ethical committee of the University Hospital Utrecht.

\section{Study design}

Proximal small intestinal (duodenojejunal) manometry was performed after a fasting period of five hours using a 3 channel solid state catheter (Sentron BV, Roden, the Netherlands; length: $210 \mathrm{~cm}$ and od: $2.5 \mathrm{~mm}$ ), incorporating micro-transducers at intervals of 5,10 , and $15 \mathrm{~cm}$ from the tip. The inter-transducer distance was chosen according to the recommendations of Waldron et al. ${ }^{21}$ The catheter was introduced at $300 \mathrm{pm}$ and positioned under fluoroscopic control with the distal transducer at the ligament of Treitz ('jejunum') and the proximal and middle transducers in the duodenum ('duodenum 1 and $2^{\prime}$ ). After positioning, the catheter was taped to the nose and attached to a portable data logger (Medical Measurement Systems, Enschede, the Netherlands).

The storage capacity of the data logger was 1 MB. With the aid of data compression a storage capacity of $1.9 \mathrm{MB}$ was reached. Intraluminal pressures were sampled at a frequency of $5 \mathrm{~Hz}$ which is double the rate required to record phasic contractions from the upper small intestine reliably. ${ }^{22} 23$ A stationary MS-DOS computer served as on line monitor and retrieval system. Before introduction of the catheter, calibration of the three transducers of the catheter was performed by linking the data logger to the computer and applying two fixed pressure levels $(0$ and $5 \mathrm{kPa}$ ) using a vertical cylinder filled with water at $37^{\circ} \mathrm{C}$. The recording was started at $400 \mathrm{pm}$. Patients and control subjects were allowed to do their normal daily activities during the measurement, but more extreme activities such as sports entailing vigorous exercise were not permitted. At $600 \mathrm{pm}$ the subjects took a standard evening meal (stew, mixed vegetables, and potatoes, containing $1805 \mathrm{~kJ}, 27 \mathrm{~g}$ protein, $29 \mathrm{~g}$ carbohydrate, and $23 \mathrm{~g}$ fat; Iglo, Utrecht, the Netherlands) with $200 \mathrm{ml}$ water.

The subjects remained fasting until the next morning. They went to bed at $10-11 \mathrm{pm}$ and set their alarm clocks for 630 am. At 700 am the subjects took a standard breakfast consisting of two slices of bread with margarine and jam $(1250 \mathrm{~kJ}, 6 \mathrm{~g}$ protein, $48 \mathrm{~g}$ carbohydrate, and $10 \mathrm{~g}$ fat) with $200 \mathrm{ml}$ water. Other food items during or between the meals and smoking were prohibited during the study. Event buttons on the portable data logger were used to record the exact times of meals, symptoms, going to bed, and rising. Each subject also kept a diary of activities pursued during the study and of the symptoms occurring during the study using the severity scores described below. The next morning at 1100 am the catheter was removed after fluoroscopical check of its position. The portable data logger was connected to the computer and the data were downloaded and archived to 3.5 inch diskettes for later analysis.

\section{Signal analysis}

The motility patterns were analysed both visually and semi-automatically. The most proximal pressure transducer in the duodenum was used to identify the phases of the MMC cycle. These phases were defined as follows: (a) phase I as motor quiescence starting immediately after the end of phase III, (b) phase III as irregular activity with contractions of $>2 \mathrm{kPa}$ occurring at a rate of more than two contractions per 10 minute, (c) phase III as regular, high amplitude contractile activity at a maximal frequency (10-12 contractions per minute in the duodenum) for at least two minutes at the distal transducer and propagated over at least two recording sites followed by motor quiescence. ${ }^{24} 25$ The MMC cycles were divided into those occurring between dinner and breakfast (night-time cycles), and those occurring before dinner and after breakfast (daytime cycles). The duration of the MMC cycle was taken as the time interval between the end of phase III in the proximal duodenum to the end of the next phase III. The postprandial period started at the time the meal was completed and ended at the beginning of the first phase III. ${ }^{25}$

Firstly, the motility patterns were analysed visually using commercially available software (Medical measurement Systems, Enschede, the Netherlands). With this program any desired time window can be displayed for analysis and the display also shows the event markers pressed by the subjects indicating all events. After identifying the fasting and postprandial periods, the number and duration of the MMC cycles and the duration of their constituent phases were determined for the total period of the study and for the daytime and night-time periods separately, because of a probable circadion rhythm. ${ }^{23} 26$ The propagation velocity of phase III activity was defined as the distance between two sensors $(\mathrm{cm})$ divided by the time interval ( $\mathrm{min}$ ) between the onset of phase III at the sensors. ${ }^{21} 2227$ The propagation of phase III activity was classified as antegrade 
or retrograde, when propagation velocity was higher than $1 \mathrm{~cm} / \mathrm{min}$ but slower than 30 $\mathrm{cm} / \mathrm{min}$. Phase III activity was judged to be simultaneous, when propagation velocity in either direction was higher than $30 \mathrm{~cm} / \mathrm{min}$. The direction of propagation of phase III (antegrade, retrograde or simultaneous) was determined by the computer program. Thereafter, automated quantitative analysis of phase II and the postprandial periods was undertaken using a software program developed in our department. The first step in this analysis consists of the calculation of baseline pressures over one minute periods. This is done by determining, for each of the signals, the minimum pressure within each minute block. Secondly, an algorithm determines, sample for sample, the lowest pressure values in the three individual pressure signals. The resulting data file, of equal length as the individual pressure files, is referred to as the 'minimum curve'. This curve is used in the elimination of artefacts induced by body movements, coughing, and straining. These artefacts occur at all transducers with similar amplitude and identical duration. By means of subtracting the minimum curve from the individual pressure curves these artefacts are eliminated. Thirdly, phasic contractions are detected. A contraction is defined as an increase in pressure exceeding baseline pressure with more than $2 \mathrm{kPa}$, lasting longer than 2.5 seconds but shorter than 10 seconds. To be accepted as a contraction the time interval between the peak and the peak of the previous contraction has to exceed three seconds. When two closely spaced contractions are detected, with an interval shorter than three seconds, the highest of the two peaks is taken as the actual contraction, the other is discarded. With this procedure a bifid pressure wave is scored as one single contraction rather than two closely spaced contractions. The characteristics of the detected contractions are stored in separate data files. These are used for the generation of schematised plots and for the automated quantitative analysis of motility variables. The contraction incidence (number of contractions per minute), mean amplitude, and motility index

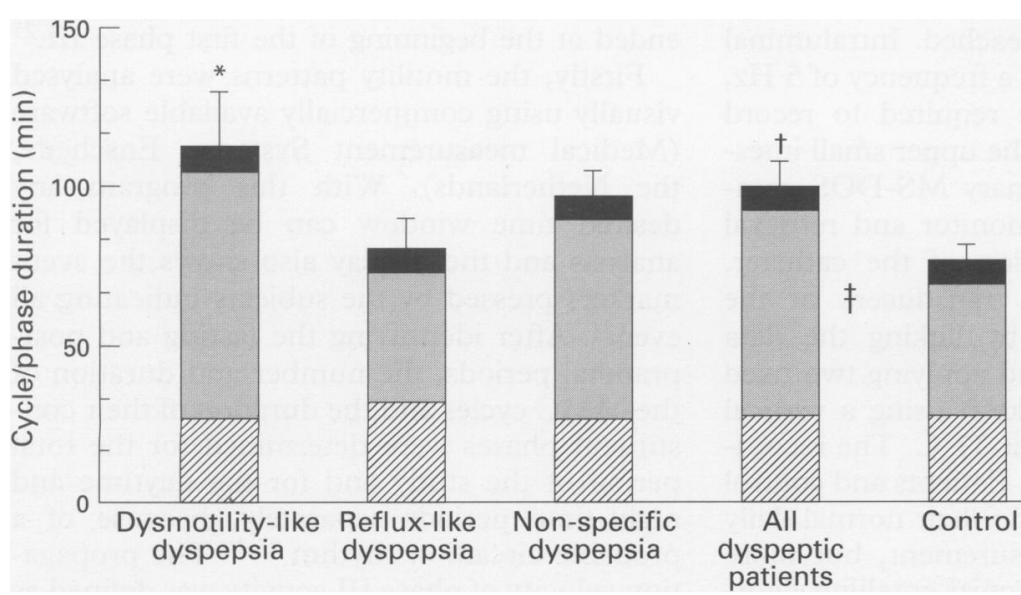

Figure 1: The length of the MMC cycles (mean (SEM)) was longer in patients with functional dyspepsia $(\dagger p=0.013)$, in particular in the subgroup dysmotility-like dyspepsia $\left({ }^{\star} p=0 \cdot 046\right)$, but not in reflux-like and non-specific dyspepsia, compared with control subjects. The duration of phase II (dotted bars), but not of phase I (striated bars) and phase III (closed bars), was longer in these patients $(\ddagger p=0 \cdot 027)$. were calculated for phase II (during a 30 minute period before phase III) and the postprandial periods (for a total period of two hours and for each 30 minute separately). The motility index was calculated using the formula $\mathrm{MI}=1 \mathrm{n}$ ((number of waves $\times$ sum of amplitudes) +1$).{ }^{28}$ In addition, the incidence and duration (in minutes) of both non-propagated and propagated clustered activity at maximum frequency lasting at least 0.5 minutes (so called burst activity) was determined visually and its duration was calculated at the distal channel. ${ }^{23} 29$

\section{Assessment of gastrointestinal symptoms}

The severity of each of the symptoms nausea, vomiting, retrosternal pain, heartburn, belching, epigastric pain, fullness, and postprandial early satiety was scored daily for one week $(0=$ absence of symptoms; $1=$ mild, symptoms noticed only when payed attention to; 2 =moderate, symptoms clearly noticed without interfering with normal daily activities; $3=$ severe, symptoms interfering with normal daily activities). This was done by the patients themselves using a questionnaire. The mean score for each individual symptom was calculated. On the basis of these scores, the patients were divided into the subgroups: dysmotilitylike dyspepsia, reflux-like dyspepsia, ulcer-like dyspepsia or non-specific dyspepsia. Therefore, the mean scores of the symptoms belonging to a subgroup were calculated and compared with the total score of all three subgroups. Patients were considered having a dysmotility-like dyspepsia if the mean score of the symptoms nausea, vomiting, belching, fullness, and early satiety constituted more than $50 \%$ of the total score; reflux-like dyspepsia if the mean score of retrosternal pain and heartburn was higher than $50 \%$ of this total score; ulcer-like dyspepsia if the mean score of epigastric pain exceeded $50 \%$ of the total score; and non-specific if none of the mean scores constituted more than $50 \%$.

The relations between symptom episodes, recorded by the event button on the data logger, and motility abnormalities (burst activity, non-propagated, and retrograde phase III activity) were analysed, using two different time windows. The first was a 10 minute time window beginning 10 minutes before and

TABLE I Contraction incidence, amplitude, and motility index (mean (SEM)) during phase II (daytime and night-time) in patients with functional dyspepsia and control subjects

\begin{tabular}{|c|c|c|c|c|}
\hline & \multicolumn{2}{|c|}{ Daytime period } & \multicolumn{2}{|c|}{ Night-time period } \\
\hline & Patients & Controls & Patients & Controls \\
\hline $\begin{array}{l}\text { Duodenur } \\
\text { Duodenur } \\
\text { Jejunum }\end{array}$ & $\begin{array}{c}\text { nce (numbe } \\
2 \cdot 2(0.3) \\
2 \cdot 6(0.3) \\
2.6(0.4)\end{array}$ & $\begin{array}{l}\min ) \\
1.4(0.3) \\
1.9(0.5) \\
1.8(0.3)\end{array}$ & $\begin{array}{l}0.9(0.1) \\
1.1(0.2) \\
1.3(0.2)\end{array}$ & $\begin{array}{l}0.9(0.1) \\
1 \cdot 1(0.2) \\
1 \cdot 1(0.2)\end{array}$ \\
\hline $\begin{array}{l}\text { Contraction amp } \\
\text { Duodenum } 1 \\
\text { Duodenum } 2 \\
\text { Jejunum }\end{array}$ & $\begin{array}{c}\text { itude }(\mathrm{kPa}) \\
3.7(0.2) \\
3.7(0.2) \\
4.2(0.3)\end{array}$ & $\begin{array}{l}3.3(0 \cdot 2) \\
3.4(0.2) \\
3.8(0.1)\end{array}$ & $\begin{array}{l}3.6(0.3) \\
3.3(0.2) \\
3.5(0.2)\end{array}$ & $\begin{array}{l}3 \cdot 3(0 \cdot 2) \\
3 \cdot 2(0 \cdot 2) \\
3 \cdot 2(0 \cdot 1)\end{array}$ \\
\hline $\begin{array}{l}\text { Motility index } \\
\text { Duodenum } 1 \\
\text { Duodenum } 2 \\
\text { Jejunum }\end{array}$ & $\begin{array}{l}7.5(0.2) \\
7.7(0.3) \\
8.0(0.3)\end{array}$ & $\begin{array}{l}7.5(0.3) \\
7.7(0.4) \\
7.7(0.3)\end{array}$ & $\begin{array}{l}9.4(0.4) \\
9.5(0.5) \\
9.8(0.4)\end{array}$ & $\begin{array}{l}8.8(0.5) \\
9.3(0.5) \\
9.4(0.2)\end{array}$ \\
\hline
\end{tabular}




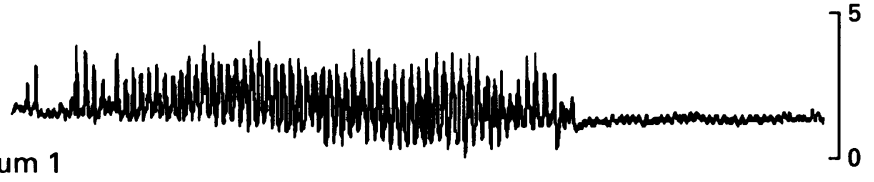

Duodenum 1

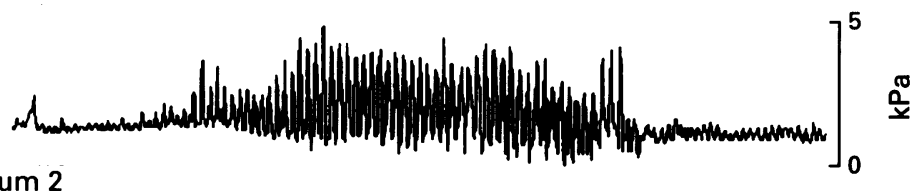

Duodenum 2

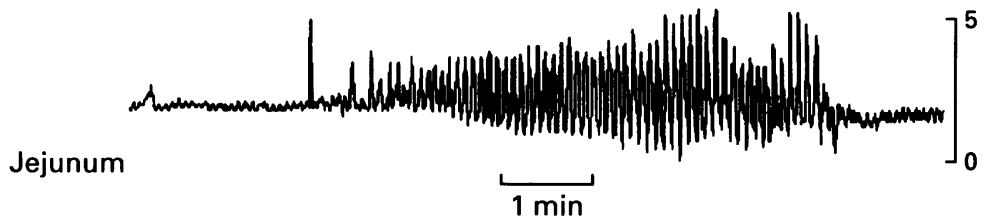

Figure 2: Antegradely propagated phase III activity in a patient with dysmotility-like functional dyspepsia.

ending at the onset of a symptom episode $(-10 / 0$ window). The second window began at the onset of a symptom episode and ended 10 minutes after the onset of a symptom episode $(0 /+10$ window $)$. For these two time windows the symptom index (SI) was calculated according to Wiener et al ${ }^{30}$ as: number of symptom episodes associated with motility abnormalities divided by the total number of symptom episodes (multiplied by $100 \%$ ).

\section{Statistical analysis}

Where there was normal distribution of the data statistical comparisons between patients and control subjects were made using Student's $t$ tests (unpaired data), otherwise the Mann-Whitney rank sum test was performed. The $\chi^{2}$ test was used to assess differences in the prevalence of burst activity, non-propagated, and propagated phase III activity. Relations between symptoms and manometric variables were examined by (rank) correlation analysis. Differences between the dyspepsia subgroups were examined by repeated measures analysis of variance. When a significant difference was detected, results were further compared for

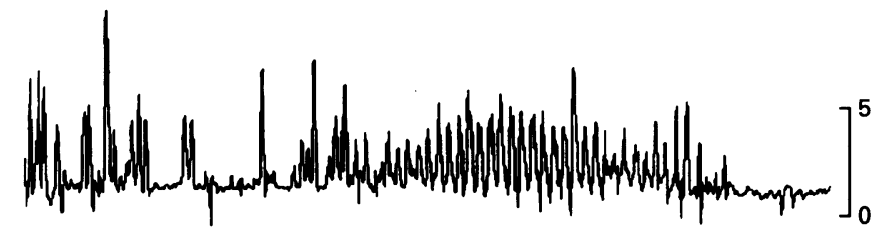

Duodenum 1

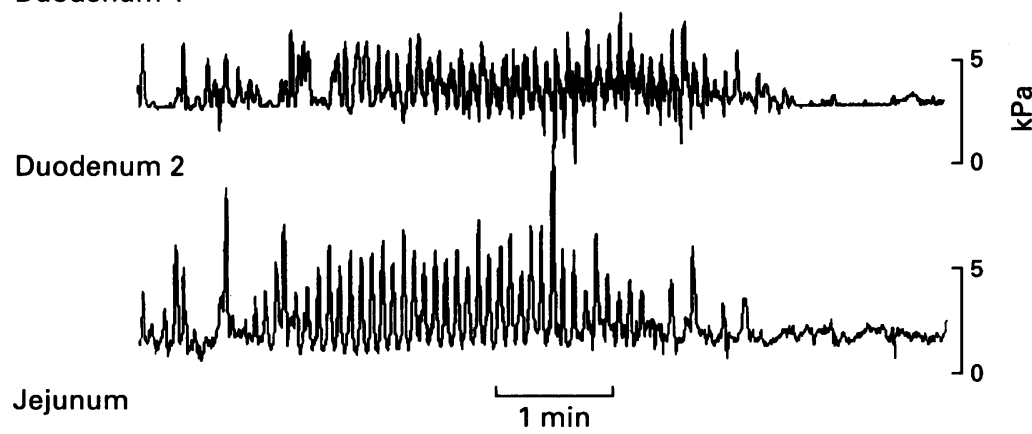

Figure 3: Retrogradely propagated phase III activity in a patient with dysmotility-like functional dyspepsia. statistical significance by Fisher's least significant difference test. The level of statistical significance was defined as a two tailed probability of $<0 \cdot 05$. This level was adjusted to the number of variables tested, using Bonferoni's correction.

\section{Results}

\section{General characteristics}

All 30 patients and 20 control subjects completed the study. In one patient the catheter was found to have migrated back into the stomach during the study and the data of this patient were discarded. Forty three per cent of the remaining 29 patients $(n=13)$ had dysmotility-like dyspepsia, $17 \%(n=5)$ had refluxlike dyspepsia, and $40 \%$ of the patients $(n=11)$ had non-specific dyspepsia. Thirty seven per cent of the patients with non-specific dyspepsia $(n=10)$ had both dysmotility-like and refluxlike symptoms and $3 \%$ of the patients $(n=1)$ also had ulcer-like symptoms. None of the patients fulfilled the criteria for ulcer-like dyspepsia. The total duration of the study in patients and control subjects was $19 \cdot 0(0 \cdot 1)$ and $18.7(0 \cdot 2)$ hours, respectively.

\section{Fasting state}

The number of MMC cycles recorded during the study was significantly lower in patients, especially in the patients with dysmotility-like dyspepsia, than in control subjects $(3.8(0.4)$, $5.3(0.7)$, and $2.6(0.5)$ cycles, respectively; $\mathrm{p}=0.048)$. Absence of complete MMC cycles was found in $10 \%$ of the patients. In the control subjects, at least one complete MMC cycle was seen during the study. As Figure 1 shows, the length of the MMC cycles was significantly longer in patients with functional dyspepsia than in control subjects. This prolonged duration of the MMC cycle in patients with functional dyspepsia was caused by a longer duration of phase II (Fig 1), both during the daytime and night-time period. During phase II the contraction incidence, mean amplitude, and motility index were not different between patients and control subjects (Table I). No differences between the groups were found in the duration of phase I and III. A shorter duration of phase I was significantly correlated with higher scores for the symptoms epigastric pain $\left(r_{\mathrm{s}}=-4.0 ; \quad \mathrm{p}=0.033\right)$, belching $\left(r_{\mathrm{s}}=-0.55 ;\right.$ $\mathrm{p}=0.007)$, and fullness $\left(r_{\mathrm{s}}=-0.46 ; \mathrm{p}=0.012\right)$. Non-propagated and retrogradely propagated phase III activity was found in $48 \%$ of the patients and in $15 \%$ of the control subjects; $p=0.020)$. In the patients, 136 of the 170 recorded phases III was antegradely propagated (Fig 2), 15 retrogradely (Fig 3), and 19 non-propagated (Fig 4), compared with 147, 1 , and 4 of the 152 phases III in control subjects, respectively $(p<0 \cdot 05)$.

\section{Fed state}

After dinner - the duration of the postprandial period was not different between patients 
Duodenum 1

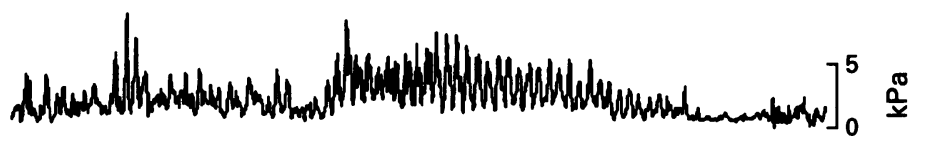

Duodenum 2

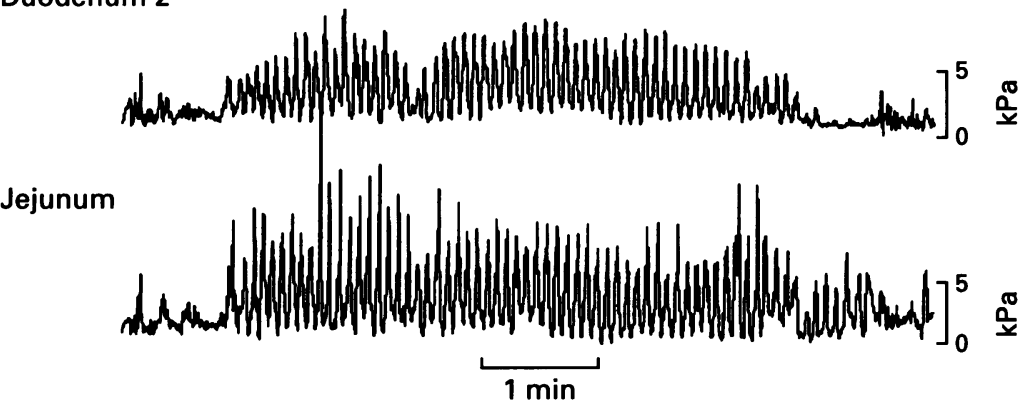

Figure 4: Non-propagated phase III activity in a patient with dysmotility-like functional dyspepsia.

and control subjects $(374 \cdot 1(32 \cdot 4)$ and $384 \cdot 8$ $(31 \cdot 2)$ minutes, respectively). In two patients, but in none of the control subjects, not a single phase III was observed between dinner and breakfast. In all patients except one, the postprandial period after dinner had a duration of more than 120 minutes. In this patient, phase III activity occurred 34 minutes after the end of the meal and was associated with symptoms of pain and nausea.

No differences were found in the contraction incidence, mean amplitude or motility index between the groups during the total (two hours) period or during each 30 minute period separately (Table II). No correlations were found between manometric parameters and symptoms scored before or during the study.

After breakfast - the duration of the postprandial period was also not different between patients and control subjects $(119 \cdot 8(10 \cdot 8)$ and $114(16 \cdot 1)$ minutes, respectively). As Table III shows, no differences were found in contraction incidence, mean amplitude or motility index during the first 90 minutes after the meal. However, $1 \frac{1}{2}$ hours after completing breakfast the motility index was higher in patients than in control subjects $(p<0.05)$, caused by an increase in the incidence of contractions. During the second hour after the meal, a positive correlation was present between the contraction incidence and symptoms scored before the study $\left(r_{\mathrm{s}}=0.39 ; \mathrm{p}=0.044\right)$, especially for pyrosis $\left(r_{\mathrm{s}}=0.43 ; \mathrm{p}=0.026\right)$.

\section{Burst activity}

Burst activity (Fig 5) was significantly more present in the patients than in the control subjects $(22 \%$ and $6 \%$ of the subjects, respectively; $p=0.003$ ), both fasting and postprandially. The mean duration of burst activity was also higher in patients than in control subjects $(22.3(6 \cdot 0)$ and $4 \cdot 8(2 \cdot 1)$ minutes, respectively; $\mathrm{p}=0 \cdot 010$ ). Burst activity was most prominent in the distal channel (jejunum).

\section{Symptom index}

During the monitoring, 25 patients had 88 symptom episodes. For each patient 3.04 $(0.63)$ symptom episodes occurred (range from 1 to 13). Eight symptom episodes were associated with motility abnormalities occurring in the $-10 / 0$ time window only, two with abnormalities in the $0 /+10$ time window only, and 36 were associated with abnormalities in both time windows. In the 10 minute window preceding the symptom episode $(-10 / 0$ window) 41 (47\%) symptom episodes were associated with burst activity and three (3\%) with non-propagated or retrogradely propagated phase III activity. In the 10 minute window after the symptom episode $(0 /+10$ window) 34 (39\%) symptom episodes were associated with burst activity and four (5\%) with non-propagated or retrograde phase III activity. Twelve of 29 patients $(41 \%)$ had a SI $>75 \%$ with the $-10 / 0$ window and nine of 29 patients $(31 \%)$ with the $0 /+10$ window.

\section{Discussion}

The ambulatory manometric recording technique, used in this study, permitted us to study patients with functional dyspepsia for a prolonged period of time and under physiological circumstances. Conventional - that is, nonambulatory, short-term manometric techniques

TABLE II Postprandial duodenal motility index (mean (SEM)) in 30 minute periods after dinner in patients with functional dyspepsia and control subjects

\begin{tabular}{|c|c|c|c|c|c|c|c|c|}
\hline \multirow[b]{2}{*}{ After dinner } & \multicolumn{2}{|l|}{$0-30 \mathrm{Min}$} & \multicolumn{2}{|l|}{ 30-60 Min } & \multicolumn{2}{|l|}{ 60-90 Min } & \multicolumn{2}{|c|}{$90-120 \mathrm{Min}$} \\
\hline & Patients & Controls & Patients & Controls & Patients & Controls & Patients & Controls \\
\hline $\begin{array}{l}\text { Duodenum } 1 \\
\text { Duodenum } 2 \\
\text { Jejunum }\end{array}$ & $\begin{array}{r}9.9(0.2) \\
10.5(0.2) \\
10.9(0.2)\end{array}$ & $\begin{array}{l}10.3(0.2) \\
10.8(0.2) \\
11 \cdot 0(0.2)\end{array}$ & $\begin{array}{r}9.6(0.2) \\
10.1(0.2) \\
10.5(0.2)\end{array}$ & $\begin{array}{r}9.9(0.2) \\
10.4(0.3) \\
10.7(0.2)\end{array}$ & $\begin{array}{r}9.5(0.2) \\
9.9(0.2) \\
10.4(0.2)\end{array}$ & $\begin{array}{r}9.4(0.2) \\
10.2(0.3) \\
10.6(0.3)\end{array}$ & $\begin{array}{r}9.4(0.2) \\
9.9(0.2) \\
10.4(0.2)\end{array}$ & $\begin{array}{r}9.1(0.3) \\
9.7(0.4) \\
10.5(0.3)\end{array}$ \\
\hline
\end{tabular}

TABLE III Postprandial duodenal motility index (mean (SEM)) in 30 minute periods after breakfast in patients with functional dyspepsia and control subjects $\left({ }^{\star} p<0.05\right)$

\begin{tabular}{|c|c|c|c|c|c|c|c|c|}
\hline \multirow[b]{2}{*}{ After breakfast } & \multicolumn{2}{|l|}{$0-30 \mathrm{Min}$} & \multicolumn{2}{|l|}{ 30-60 Min } & \multicolumn{2}{|l|}{ 60-90 Min } & \multicolumn{2}{|c|}{ 90-120 Min } \\
\hline & Patients & Controls & Patients & Controls & Patients & Controls & Patients & Controls \\
\hline $\begin{array}{l}\text { Duodenum } 1 \\
\text { Duodenum } 2 \\
\text { Jejunum }\end{array}$ & $\begin{array}{l}10.0(0.2) \\
10.5(0.2) \\
10.8(0.2)\end{array}$ & $\begin{array}{l}10.2(0.2) \\
10.6(0.2) \\
10.9(0.2)\end{array}$ & $\begin{array}{r}9.6(0.2) \\
9.9(0.2) \\
10.5(0.2)\end{array}$ & $\begin{array}{r}9 \cdot 7(0.2) \\
10 \cdot 1(0.3) \\
10.5(0.3)\end{array}$ & $\begin{array}{r}9.5(0.2) \\
9.7(0.2) \\
10.3(0.2)\end{array}$ & $\begin{array}{r}9.5(0.3) \\
10 \cdot 1(0 \cdot 3) \\
10 \cdot 2(0.2)\end{array}$ & $\begin{array}{r}9 \cdot 2(0 \cdot 2) \\
10 \cdot 1(0.3) \\
10 \cdot 2(0.2)\end{array}$ & $\begin{array}{l}7.9(0.4)^{\star} \\
7.7(0.3)^{\star} \\
8.8(0.3)^{\star}\end{array}$ \\
\hline
\end{tabular}


Duodenum 1

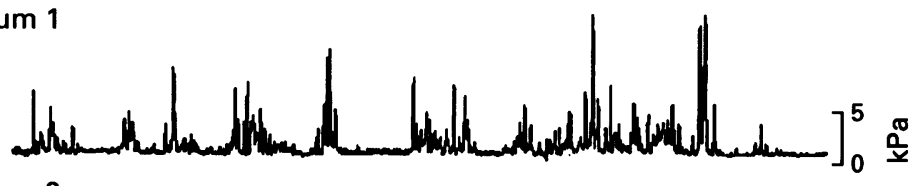

Duodenum 2

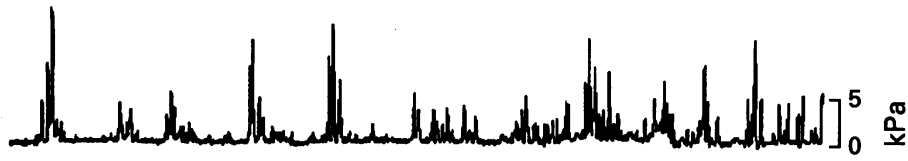

Jejunum

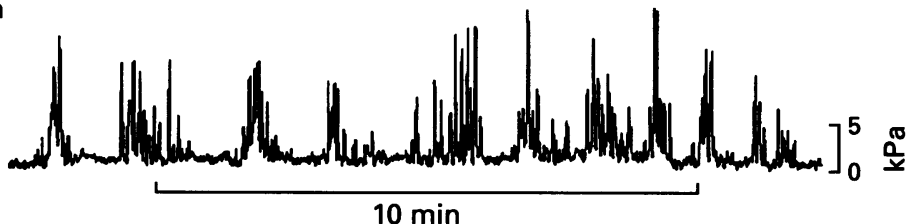

$10 \mathrm{~min}$

Figure 5: Burst activity in a patient with dysmotility-like functional dyspepsia. This motor abnormality was associated with symptoms of nausea and belching.

have the advantage that motility is studied under standardised conditions. However, even in non-ambulatory studies considerable interindividual variability of small bowel motility is seen. $.^{25} 31-33$ Theoretically, variability of the manometric parameters induced by physical activity is a limitation of the ambulatory recording technique. However, this technique provides the user with much more manometric information, especially in the fasting state.

Our study was performed in 30 patients and 20 healthy volunteers. The measurement was well tolerated. Only in one patient did the catheter migrate back into the stomach during the study and data analysis was not possible. A computerised analysis program, developed in our department, permitted rapid interpretation and evaluation of the considerable amount of data acquired during such prolonged monitoring.

In patients with functional dyspepsia, defined according to the criteria published by a working party, ${ }^{2}$ several abnormalities of the small intestinal motor patterns were seen. In the patients, especially in those with dysmotility-like dyspepsia, the duration of the MMC cycles was longer and MMC cycles occurred less frequently than in control subjects. This abnormality might lead to delayed interdigestive transit through the small intestine and to dyspeptic symptoms in these patients. The significantly higher incidence of non-propagated and retrogradely propagated phase III activity in the dyspeptic patients might have similar effects. Clusters of contractions, so called burst activity, were seen in healthy control subjects, but more frequently in patients with functional dyspepsia, both during fasting and postprandially. These bursts seem to be non-specific as they are also found in patients with a partially obstructed bowel, in diabetic patients, and in patients with the irritable bowel syndrome. 282934 However, previous reports showed a close temporal relation between burst activity and abdominal symptoms. 3435 Our findings support the existence of such a relation in patients with functional dyspepsia.

In analogy with 24 hour oesophageal monitoring, we used the SI, defined as the number of symptom episodes associated with dysmotility divided by the total number of symptom episodes (multiplied by $100 \%$ ), to correlate symptoms and motility abnormalities. In addition to a window preceding symptom onset, also a window after the onset of a symptom episode was used. This was done to investigate the possibility that symptoms were the cause rather than the effect of intestinal dysmotility, as it has been shown that motor abnormalities can be induced by stress. ${ }^{36}$ Symptom induced motor abnormalities were made unlikely by the finding that a motor abnormality occurred only in two patients in the $0 /+10$ minute time window after the onset of a symptom episode. In eight patients, motor abnormalities occurred in the $-10 / 0$ window and in 36 patients abnormalities were seen both in the $-10 / 0$ and $0 /+10$ window. In view of the prevalence of these motor abnormalities, a coincidence with symptoms seems to be of lesser probability.

In conclusion, our results suggest that motor abnormalities of the small intestine participate in the pathogenesis of dyspeptic symptoms in patients with functional dyspepsia. These motor abnormalities are more pronounced during fasting than postprandially. Variability of the manometric parameters induced by physical activity seems to be a limitation of ambulatory recordings. Ambulatory manometry of the small intestine provides a valuable tool to assess correlations between dysmotility and symptoms in outpatients, who pursue their normal daily activities.

1 Jones R, Lydeard S. Prevalence of symptoms or dyspepsia in the community. Lancet 1989; i: 47-51.

2 Colin-Jones DG, Bloom B, Bodemar G, Crean GP, Freston $\mathrm{J}$, Gugler R, et al. Management of dyspepsia: report of a working party. Lancet 1988; i: 576-9.

3 Talley NJ, Phillips SF. Non-ulcer dyspepsia: potential causes and pathophysiology. Ann Intern Med 1988; 108: 865-79.

4 Waldron B, Cullen PT, Kumar R, Smith D, Jankowski J, Hopwood D, et al. Evidence for hypomotility in non-ulcer dyspepsia: a prospective multifactorial study. Gut 1991; dyspepsia: a

5 Nyrén O, Adami H-O, Gustavsson S, Lindgren PG, Lööf L, Nyberg A. The 'epigastric distress syndrome': a possible disease entity identified by history and endoscopy in patients with non-ulcer dyspepsia. $\mathcal{f}$ Clin Gastroenterol 1987; 9: 303-9.

6 Gotthard R, Bodemar G, Jöhnsson K-Å, Walan A. Comparison between non-ulcer dyspepsia patients with and without endoscopic antral gastritis. Scand $\mathcal{f}$ Gastroenterol 1984; 19: 22 .

7 Jöhnsson K-Â, Gotthard R, Bodemar G, Brodin U. The clinical relevance of endoscopic and histologic inflammation in gastroduodenal mucosa in dyspepsia of unknown tion in gastroduodenal mucosa in dyspepsia of
origin. Scand $\mathcal{F}$ Gastroenterol 1989; 24: 385-95.

8 Tucci A, Corinaldesi R, Stanghellini V, Tosetti C, Di Febo $\mathrm{G}$, Paparo GF, et al. Helicobacter pylori infection and gastric function in patients with chronic idiopathic dyspepsia. Gastroenterology 1992; 103: 768-74.

9 Loffeld RJLF, Potters HVJP, Stobbering E, Flendrig JA Van Spreeuwel JP, Arends JW. Campylobacter-associated gastritis in patients with non-ulcer dyspepsia: a doubleblind, placebo-controlled trial with colloidal bismuth subcitrate. Gut 1989; 30: 1206-12.

10 Malagelada J-R, Stanghellini V. Manometric evaluation of functional upper gut symptoms. Gastroenterology 1985; 88: 1223-35.

11 Kerlin P. Postprandial antral hypomotility in patients with idiopathic nausea and vomiting. Gut 1989; 30: 54-9.

12 Talley NJ, Piper DW. Major life events stress and dyspepsia of unknown cause: a case control study. Gut 1986; 27: of unknow.

13 Talley NJ, Fung LH, Gilligan IJ, McNeil D, Piper DW. Association of anxiety, neuroticism, and depression with dyspepia of unknown cause. A case control study. Gastroenterology 1986; 90: 886-92.

14 Greydanus $M$, Vassallo $M$, Camilleri $M$, Nelson DK, Hanson RB, Thomforde GM. Neurohormonal factors in functional dyspepsia: insights on pathophysiological mechanisms. Gastroenterology 1991; 100: 1311-8. 
15 Jian R, Ducrot F, Ruskone A. Symptomatic radionuclide and therapeutic assessment of chronic idiopathic dyspepsia. A double-blind placebo-controlled evaluation of cisapride. Dig Dis Sci 1989; 34: 657-64.

16 Wegener M, Börsch G, Schaffstein J, Schult-Flacke C, Mai U. Does gastric campylobacter pylori colonization cause delay of gastric emptying in non-ulcer dyspepsia? $A m \mathcal{F}$ delay of gastric emptying in
Gastroenterol 1988; 38: 737-40.

17 Wengrower D, Zaltzman S, Karmeli F, Goldin E. Idiopathic gastroparesis in patients with unexplained nausea and vomiting. Dig Dis Sci 1991; 9: 1255-8.

18 Lockerman ZS, Maurer A, Siegel J. Clinical profiles for idiopathic, diabetic and postsurgical gastroparesis: a disorder occurring predominantly in women. Gastroenterology 1987; 92: 1508-16.

19 Stanghellini V, Ghidini C, Ricci Maccarini M, Paparo GF, Corinaldesi R, Barbara L. Fasting and postprandial gastrointestinal motility in ulcer and non-ulcer dyspepsia. Gut 1992; 33: 184-90.

20 Bassotti G, Pelli MA, Morelli A. Duodenojejunal motor activity in patients with chronic dyspeptic symptoms. $\mathcal{f}$ Clin Gastroenterol 1990; 12: 17-21.

21 Waldron B, Smith D, Storey BE, White G, Campbell FC. Development and validation of microcomputer analysis of gastric and small-bowel manometry. $\mathcal{f}$ Gastrointest Motil 1992; 4: 301-15.

22 Husebye E, Skar V, Aalen OO, Osnes M. Digital ambulatory manometry of the small intestine in healthy adults. Dig Dis Sci 1990; 9: 1057-65.

23 Benson MJ, Castillo FD, Deeks J, Wingate DI. Assessment by prolonged ambulatory manometry of the effect of oral cisapride on proximal small bowel interdigestive motility. Dig Dis Sci 1992; 10: 1569-75.

24 Remington M, Malagelada J-R, Zinsmeister A, Fleming CR. Abnormalities in gastrointestinal motor activity in patients with short bowels: effects on synthetic opiate. Gastroenterology 1983; 85: 629-36.
25 Kellow JE, Borody TJ, Phillips SF, Tucker RL, Haddad AC. Human interdigestive motility: variations in pattern from oesophagus to colon. Gastroenterology 1986; 91 : 386-95.

26 Kumar D, Wingate D, Ruckebusch Y. Circadian variation in the propagation velocity of the migrating motor complex. Gastroenterology 1986; 91: 926-30.

27 Stanghellini V, Camilleri M, Malagelada J-R. Chronic idiopathic intestinal pseudo-obstruction: clinical and intestipathic intestinal pseudo-obstruction: clinical

28 Abell TL, Camilleri M, Hench VS, Malagelada J-R. Gastric electromechanical function and gastric emptying in diabetic gastroparesis. Eur $\mathcal{F}$ Gastroenterol Hepatol 1991; 3: 163-7. 29 Summers RW, Anuras S, Green J. Jejunal manometry in health, partial obstruction, and pseudoobstruction Gastroenterology 1983; 85: 1290-300.

30 Wiener GJ, Richter JE, Copper JB, Wu WC, Castell DO. The symptom-index: a clinically more important parameter of ambulatory $24-\mathrm{h}$ esophageal pH monitoring. $A m$ f Gastroenterol 1988; 83: 358-61.

31 Kerlin P, Phillips S. Variability of motility of the ileum and jejunum in healthy humans. Gastroenterology 1982; 82:

32 Dooley CP, Di Lorenzo C, Valenzuela JE. Variability of migrating motor complex in humans. Dig Dis Sci 1992; 37: 723-8.

33 Quigley EMM. Intestinal manometry: Technical advances, clinical limitations. Dig Dis Sci 1992; 37: 10-3

34 Kellow JE, Phillips SF. Altered small bowel motility in irritable bowel syndrome is correlated with symptoms. Gastroenterology 1987; 92: 1885-93.

35 Kumar D, Wingate DL. The irritable bowel syndrome: a paroxysmal motor disorder. Lancet 1985; ii: 973-7.

36 Valori RM, Kumar D, Wingate DL. Effects of different types of stress and of 'prokinetic drugs' on control of the fasting motor complex in humans. Gastroenterology 1986; 90: 1890-900. 